\title{
Editorial: Assessment in psychology in the 21st century - a multi-layered endeavour
}

\author{
Kobus Maree \\ University of Pretoria \\ kobus.maree@up.ac.za
}

It will surely come as no surprise that assessment features prominently in virtually every article in this issue - after all, assessing and diagnosing clients is central in the practice of psychologists in every category of registration (Motsoaledi, 2010).

The science of assessment, the standardisation of existing instruments and the development of new assessment instruments are all proceeding well in South Africa and excellent work continues to be done in this field. However, the number of researchers engaged in this key activity remains unacceptably small, and I have, accordingly, devoted the first part of this editorial to a brief exposition of the need for greater involvement of psychologists in this area.

Psychology as a profession has in recent years seen numerous changes globally, and changes in people's lifestyles have brought fresh challenges to psychological assessment practice. The new century is characterised by increasing stress levels, economic challenges and accompanying increases in mental health diseases. Numerous challenges are facing psychological assessment practice in the 21 st century, and the practice will have to meet these challenges if it is to remain relevant to postmodern society. Local academics and practitioners have repeatedly expressed their concern that most assessment instruments were developed some time ago or were not standardised on a representative sample of the South African population. The schism between qualitative assessment and quantitative assessment also still haunts the field.

Psychology theory, practice and assessment globally have been accused of failing to address the needs of non-white, non-western, non-'standard' populations (MacMahon \& Patton, 2002). Objective methods in psychology in the past often disregarded the subjective and personal meaning people attach to their lives despite the increased emphasis on personal meaning and acceptance of the fact that the therapeutic relationship narrows the gap between counselling and psychotherapy (Savickas, 1993).

It is therefore not surprising that calls have been made internationally for changes in the profession. Increased focus is evident on objective as well as subjective aspects of assessment. Qualitative assessment strategies are, for instance, used to explore clients' life stories and to place questionnaire results (such as aptitude, interests and values) in context. It is cause for concern that shifts are taking place globally towards acceptance of qualitative approaches in career counselling, yet South African institutions of higher education are, by and large, still clinging to the traditional, positivist model. Even in 2010, few South African training institutions have embraced a qualitative-quantitative approach. Career counselling here continues to be characterised by psychometric assessment procedures - by what Stead and Watson (1998) call 'proven' assessment methods despite Savickas' contention that counsellors should be looking for an approach that 'enables rather than fits' (Savickas, 1993; 2004).

In the next few years, the following questions will require answers:

- Is it still the (largely black) rural and township sector that is being disadvantaged by the lack of appropriate assessment instruments, and how can this situation be changed?

- In what ways does the lack of assessment instruments impact on the practice of psychological assessment in South Africa, and how can this challenge be met?

- How does the lack of assessment instruments impact on intervention and how can this challenge be met? 
- What is the longer term outlook for psychological assessment practice in 21 st century South Africa?

- Should the focus be on quantitative assessment or on qualitative assessment or is the ideal a combined quantitative-qualitative approach?

Many colleagues have criticised eurocentric assessment models and have called for research on approaches that would more satisfactorily take a developing (African) country perspective into account. Is this a viable idea whose time has come? Can models developed in North America, for instance, be adapted and implemented in such a way as to impact positively on the current state of psychological assessment practice in South Africa? Or should we do our own research and develop models that are better suited for assessment in developing countries? Can we realistically hope to achieve this aim? The answer seems to lie somewhere in between. Instead of adopting an and/or approach, an inclusive approach may be preferable, that is, using what is available while at the same time developing our own theoretical models and basing our assessment instruments on these models.

Against this background, the contributions in this issue should be of interest to psychologists locally and further afield.

\section{What readers can expect in this issue}

The contributors to this guest issue have individually and collectively succeeded in identifying hiatuses in the literature and suggesting ways of filling them. As the SAJP prides itself on being a channel of critical inquiry rather than advocacy writing, I welcome these critical voices and trust that they will stimulate constructive debate. As always, readers should not expect clear-cut, uniform 'answers' to all the questions raised. Instead, they should make up their own minds on the various issues. After all, the contributions stem from the authors' own perspectives, which are, of necessity, bound in a unique location, time and space.

It is well known that first-year university students face many challenges that affect their chances of graduating as is reflected in the high failure and drop-out rates nationally. This raises questions about the effectiveness of these students' support structures. In the lead contribution, Sources of stress and support among rural-based first-year university students: an exploratory study, Anthony Pillay and Humphrey Ngcobo (2010) investigate this issue and report that approximately a quarter of the research sample considered their siblings and health professionals unsupportive. The students younger than 21 were, for example, more affected by conflict with and between their parents than their over- 21 counterparts. The authors analyse the study results in depth taking into account socioeconomic as well as gender and developmental variables.

Early-onset bipolar mood disorder manifests in the lives of many children but is often either misdiagnosed or its prevalence is underestimated, frequently with major negative implications for those involved. In the second contribution, Bipolar Mood Disorder in children and adolescents: in search of theoretic, therapeutic and diagnostic clarity, Bruce Bradfield (2010) clarifies some of the risk factors associated with paediatric bipolar disorder. Bradfield proposes a treatment procedure based on cognitive-behavioural, narrative and family systems theories in tandem with the development of pharmacological interventions. Shortcomings in psychiatric interventions are highlighted, and a framework for treatment is provided.

As indicated in the introduction, the multiple challenges posed by cultural and language bias in assessing South African patients require urgent attention (Swartz, Drennan \& Crawford, 1997, in Mosdell, Balchin \& Ameen, 2010). In the third contribution to this guest issue, Adaptation of aphasia tests for neurocognitive screening in South Africa, Jill Mosdell, Ross Balchin and Ozayr Ameen (2010) describe the adaptation of two aphasia tests - the Cookie Theft Test and the Boston Naming Test - to help eliminate western cultural, language and education bias in neurocognitive screening in South Africa. The adapted tests were piloted by testing 30 neurocognitively intact controls consisting of equal numbers of Afrikaans, English and Xhosa speakers whose scores were 
compared to their performances in the original tests. The test adaptations improved the performance of the controls over the original versions leading the authors to conclude that the adapted tests should be able to screen for aphasia. This contribution shows how quantitative and qualitative elements can be combined to develop a scientifically based, client-friendly assessment instrument.

Although the standardised version of the Wechsler Adult Intelligence Scale-III (W AIS-III) for English-speaking South Africans is widely used, and an Afrikaans translation of the verbal subtests of the WAIS-III is provided in the manual, this translation has not been standardised. In the fourth contribution, A preliminary investigation of the suitability of the WAIS-III for Afrikaans-speaking South Africans, Grieve and Van Eeden (2010) report that the performance of an urbanised sample with good quality education compared well with the performance of similar groups tested with the English version. In addition to teasing out various aspects of their results, and indicating the limitations of the study, the authors stress the importance of considering an individual's background and context when interpreting test scores.

In the fifth contribution, Effect of a course in research methods on scientific thinking among psychology students, Ashraf Kagee, Saalih Allie and Anthea Lesch (2010) refer to the broad purposes of teaching any science-based discipline as comprising a body of broadly accepted knowledge on the one hand and the processes that lead to the creation and legitimatisation of knowledge in the discipline on the other. By implementing a quasi-experimental design in their study, the authors endeavoured to determine the effect of a course in research methods on undergraduate students' ability to reason scientifically. A non-significant difference between the groups at pre-test and a significant difference at post-test was found, which led the authors to conclude that the research methods course was indeed responsible for raising the students' level of scientific thinking. "For psychology to be able to make superior knowledge claims about human nature as opposed to lay, popular, and folk understandings it is essential that psychology curricula incorporate explicit strands that address the way in which scientific knowledge about human behaviour is constructed" (Kagee, Allie \& Lesch, 2010).

Despite the changes that have taken place across the world over the past few decades, male dominance and privilege still characterise society and continue to shape postmodern reality. In her article, The crown prince and the frog-prince: characterisations in the identity construction of firstborn males, Gertina van Schalkwyk (2010) investigates identity construction and the narrative self of firstborn males with the help of metaphors from the "Frog King" fairytale. In analysing the narratives of two firstborn males who are explaining images of the crown prince and the frog-prince, the author seeks to find conceptual links between the crown prince, the frog-prince and the dominant discourse of patriarchy in identity construction.

In Foucault and individual autonomy, Bert Olivier (2010) reflects on a question that has intrigued philosophers over the centuries: What does it mean to be autonomous? Olivier argues that Foucault provides us with a model for autonomy in a psychical as well as an ethical sense and that this model is worth emulating given the structure and functioning of contemporary society, which tends to reduce individuals to passive entities.

In the eighth article, Determination of Differential Bundle Functioning (DBF) ofnumeracy and literacy tests administered to Grade 3 learners in South Africa, Joseph Wa Kivilu (2010) analyses data gathered for the Assessment Modelling Initiative (AMI) whose aim is to develop assessment materials in literacy and numeracy for learners in Grade 3 that can be used by teachers in classroom instruction and for learner assessment. In his study, Wa Kivilu found that the literacy test exhibited Differential Item Functioning (DIF) at item level and DBF at bundle level. He calls for further analysis to identify other factors that could cause DIF and DBF.

The situation of street children continues to exercise the minds of academics and scholars throughout the world. In the ninth contribution, The hidden resilience of street youth, Macalane Malindi and Linda Theron (2010) argue that resilience among street children often goes unnoticed 
because these children are widely categorised as highly vulnerable and in need of continuous care and support - a deficit view that ignores the assets and resources that enable them to develop resilience. The authors' research provides evidence that street youth develop resilience by drawing on (unconventional) personal resources and by bonding with others in their peer group who also experience the vicissitudes of life on the streets.

In their article, "Complex Trauma": reflections on the effect of early childhood abuse among a small adult group of bariatric patients, Hermann Liebenberg and Maria Papaikonomou (2010) describe a qualitative research paradigm and social constructivist epistemology that is supported by an exploratory case study design aimed at exploring the experience of early traumatic exposure, obesity and the paradoxical forced behavioural intervention experienced by a small group of participants who underwent bariatric surgery to treat a chronic disease (such as obesity). The authors conclude that adaptation to positive and/or negative life stressors can be a major concern for obese patients and report that this group of bariatric patients presented with symptoms of childhood trauma, that is, symptoms associated with complex trauma.

Few South African studies have investigated family resilience and the resiliency of families living with children diagnosed with AD/HD. The penultimate article, Resilience in families living with a child diagnosed with hyperactivity/attention deficit disorder, by Ottilia Brown, Greg Howcroft and Tania Muthen (2010) is therefore to be welcomed as it explores and describes factors that facilitate adjustment and adaptation in families after a child has been clinically diagnosed with $\mathrm{AD} / \mathrm{HD}$. The authors acknowledge that their quantitative and qualitative analyses yielded discrepant results but also some commonalities. Sample participants demonstrated their ability to recover from adversities, contrary to the findings of previous research.

Matteo and Pierluigi (2008, in Jithoo, 2010), contend that fear of cancer is particularly unsettling because it resonates with the fear of death, pain, uncertainty and powerlessness. With the exception of AIDS, no disease gives rise to greater insecurity and fear than cancer. In the final article, To tell or not to tell; the childhood cancer conundrum: parental communication and information-seeking, Vinitha Jithoo (2010) argues that information-seeking and good communication are increasingly important in helping people cope with (their fear of) cancer. The study investigates parents' perceptions of their knowledge-seeking behaviour and their experience of the communication process. It also identifies the support and guidance they may have wanted. The author concludes that communication is not always desired or required and that psychosocial support could facilitate understanding of the cognitive, social and emotive trajectory associated with childhood cancer.

As always, the contributions in this issue are diverse in terms of institution, gender and national/ international profile. We again wish to invite established as well as emerging black researchers in particular to use the SAJP as an outlet for their publications. We also request colleagues to help us review articles and to submit their reviews within the time allocated for this critical task. Sadly, we still experience considerable difficulty in soliciting a sufficient number of reviews to help us arrive at an informed decision regarding acceptance or rejection of articles. We realise that reviewing is a selfless and often time-consuming task for which you receive little recognition, but you can be sure that your support is greatly appreciated. Reviewers receive three CPD points for each article reviewed, one of which is for ethics.

Please submit your contributions to stimulate debate on all aspects of psychology in South Africa, Africa and abroad and to expand the existing network of scholars working in this field in South Africa, in the SADC region and in the rest of the world. Should you have any ideas for improving the SAJP, please feel free to contact me personally (kobus.maree@up.ac.za). Your feedback is important to us and will help shape the future direction of the journal.

In conclusion, I wish to thank all colleagues involved in the editorial and publishing process for 
their help and dedication: our Associate Editors, Willy Nel and Martin Strous (who, incidentally, also double as copy editors), our Consulting Editor, Anthony Pillay, our Consulting Editor: Statistics, Tyrone Pretorius, our Publishing Editor, Erna Kinsey, our editorial assistant, Temi Nkambule, Fatima Seedat and Nosipho Phathi at the PsySSA offices, and Tim Steward, for his thoughtful editing of the editorial.

Enjoy reading this issue of SAJP

\section{Kobus Maree}

\section{REFERENCES}

Bradfield, B.C. (2010). Bipolar mood disorder in children and adolescents: in search of theoretic, therapeutic and diagnostic clarity. South African Journal of Psychology, 40, 241-249.

Brown, O., Howcroft, G., \& Muthen, T. (2010). Resilience in families living with a child diagnosed with hyperactivity/attention deficit disorder. South African Journal of Psychology, 40, 338-350.

Grieve, K.W., \& Van Eeden, R. (2010). A preliminary investigation of the suitability of the WAIS-III for Afrikaans-speaking South Africans. South African Journal of Psychology, 40, 262-271.

Jithoo, V. (2010). To tell or not to tell; the childhood cancer conundrum: parental communication and information-seeking. South African Journal of Psychology, 40, 351-360.

Kagee, A., Allie, S., \& Lesch, A. (2010). Effect of a course in research methods on scientific thinking among psychology students. South African Journal of Psychology, 40, 272-281.

Liebenberg, H., \& Papaikonomou, M. (2010). "Complex Trauma”: reflections on the effect of early childhood abuse among a small adult group of bariatric patients. South African Journal of Psychology, 40, 327-337.

Malindi, M.J., \& Theron, L.C. (2010). The hidden resilience of street youth. South African Journal of Psychology, 40, 318-326.

Matteo, B., \& Pierluigi, B. (2008). Descriptive survey about the causes of illness given by parents of children with cancer. European Journal of Oncology Nursing, 12, 134-141.

McMahon, M., \& Patton, W. (2002). Using qualitative assessment in career counselling. International Journal for Educational and Vocational Guidance, 2, 51-66.

Mosdell, J., Balchin, R., \& Ameen, O. (2010). Adaptation of aphasia tests for neurocognitive screening in South Africa. South African Journal of Psychology, 40, 250-261.

Motsoaledi, A. (2010). Regulations defining the Scope of Practice of Practitioners of the Profession of Psychology. Pretoria: Government Gazette.

Olivier, B. (2010). Foucault and individual autonomy. South African Journal of Psychology, 40, 292-307.

Pillay, A.L., \& Ngcobo, H.S.B. (2010). Sources of stress and support among rural-based first-year university students: an exploratory study. South African Journal of Psychology, 40, 234-240.

Savickas, M.L. (1993). Career counselling in the post-modern era. Journal of Cognitive Psychotherapy: An International Quarterly, 7, 205-215.

Savickas, M.L. (2004). Career as story. Using life themes in counseling. 13th AACC National Conference, Coolangatta, Australia, 14 April 2004.

Stead, G.B., \& Watson, M.B. (1998). Career research in South Africa: challenges for the future. Journal of Vocational Behavior, 52, 289-299.

Swartz, L., Drennan, G., \& Crawford, A. (1997). Changing Language policy in mental health services - a matter of interpretation? In D. Foster, M. Freeman, \& Y. Pillay (Eds), Mental health policy issues for South Africa (pp. 167-180). Medical Association of South Africa: Multimedia Publications.

Van Schalkwyk, G.J. (2010). The crown prince and the frog-prince: characterisations in the identity construction of firstborn males. South African Journal of Psychology, 40, 282-291.

Wa Kivilu, M.J. (2010). Determination of Differential Bundle Functioning (DBF) of numeracy and literacy tests administered to Grade 3 learners in South Africa. South African Journal of Psychology, 40, 308-317. 